\title{
STUDY OF BIODIESEL PRODUCTION BY HETEROGENEOUS CATALYSIS USING MAGNETIC NANOPARTICLES SUPPORTED IN SILICA IN A PACKED BED REACTOR
}

\author{
A. P. BOURY ${ }^{1}$, A. J. O. ZUSSA ${ }^{1}$, C. A. T. CAMPOS ${ }^{1}$, M. S. FELIX ${ }^{1}$, M. S. FELIX ${ }^{1}$, M.P.A. MARIN ${ }^{1}$, L. \\ F. P. FERREIRA ${ }^{1}$, N. L. FERREIRA ${ }^{1}$, S. H. TOMA ${ }^{2}$, M. M. TOYAMA ${ }^{1}$ \\ ${ }^{1}$ Centro Universitário FEI, Departamento de Engenharia Química, São Bernardo do Campo, São Paulo, Brazil \\ ${ }^{2}$ Instituto de Química da Universidade de São Paulo - USP - LQSN, São Paulo, São Paulo, Brazil \\ ${ }^{*}$ Corresponding author. Centro Universitário FEI, Departamento de Engenharia Química, São Bernardo do Campo, São Paulo, Brazil, Phone: +55 11 43532900 \\ e-mail addressl: mtoyama@fei.edu.br (M.M. Toyama).
}

\begin{tabular}{l} 
A R T I C L E I N F O \\
\hline Article history: \\
Received 2018-12-20 \\
Accepted 2019-03-01 \\
Available online 2019-03-08 \\
pa la v r a $s$ - ch a ve \\
Reator de leito fixo \\
Nanopartícula \\
sílica \\
Transesterificação \\
ke ywords \\
Packed Bed Reactor \\
Nanoparticle \\
silica \\
Transesterification
\end{tabular}

\begin{abstract}
A B S T R A C T
In this work the biodiesel production was studied through heterogeneous catalysis using SPIONs in silica. The reaction was conducted in a fixed bed reactor immersed in thermostated bath to maintain the temperature at $60{ }^{\circ} \mathrm{C}$ using 1:6:5 (soybean/methanol/tert-butanol) molar ratios between reagents and reaction times of 6,8 and 10 hours. The reactions were also conducted in Erlenmeyer incubators at Shaker under the same conditions of molar ratios and temperature, with agitation of $300 \mathrm{rpm}$, samples being withdrawn from time to time ranging from 0.25 to 8 hours. The results showed that when the reaction was conducted in a fixed bed reactor the best conversion was achieved in batch of 10 hours being equal to $3.18 \%$ and that when incubated in Shaker a conversion of $36.04 \%$ in 8 hours. In this study the kinetic constant was also determined from the experiments incubated at Shaker and proposed a transesterification process model using the ASPEN PLUS $(R)$ process simulator.
\end{abstract}




\section{NOM E N C L A T UR E}

SPIONs superparamagnetic nanoparticles of iron oxide

$C_{A, i} \quad$ concentration of each ester (i) present at the aliquot $\left[\mathrm{mg} \mathrm{mL}^{-1}\right.$ ]

$a_{i} \quad$ coefficient for each ester [unitless]

$A_{\text {pico,i }} \quad$ area of each peak obtained on the chromatogram [unitless]

$m_{A, i} \quad$ mass of each ester in the sample [mg]

$V_{d} \quad$ volume of hexane used in the dilution $[\mathrm{mL}]$

$\mathrm{f}_{A, i} \quad$ mass fraction of ester presents in the aliquot [unitless]

$\mathrm{m}_{\mathrm{aliq}} \quad$ total mass of the aliquot used for dilution [mg]

$\mathrm{m}_{i, t} \quad$ total mass of each ester $[\mathrm{g}]$

$\mathrm{m}_{\text {exp }} \quad$ mass of the methyl ester-containing phase [mg]

$\mathrm{n}_{i, t} \quad$ number of mols of each methyl ester [mol]

$\mathrm{M}_{i} \quad$ molar mass of each ester $\left[\mathrm{g} \mathrm{mol}^{-1}\right]$

$n_{\text {bprod }} \quad$ number of mols of biodiesel obtained [mol]

$X \quad$ biodiesel converction [\%]

$M_{\text {oil }} \quad$ molar mass of soybean oil $\left[\mathrm{g} \mathrm{mol}^{-1}\right]$

$m_{\text {oil }} \quad$ mass of soybean oil [g]

$n_{\text {bprod }}$ number of mols of biodiesel [mol]

\section{INTRODUCTION}

Most of the energy consumed in the world comes from oil, coal and natural gas. However, these are non-renewable sources and are expected to be exhausted in the near future. In addition to being exhaustible, the largest deposits are located in politically conflicting regions. In addition, fossil fuels are very polluting, affecting the environment in a very aggressive way, which makes the world population seek solutions to such problems. The search for alternative fuels has been gaining prominence in the last decades, being motivated by environmental, economic and social factors. In this context, an alternative that has been highlighted is the production of biodiesel (CARVALHO, 2008; OLIVEIRA; SUAREZ; SANTOS, 2008).

Biodiesel is defined as a monoalkyl ester of naturally occurring lipid-derived fatty acids and can be produced along with glycerol through the transesterification reaction consisting of the formation of esters from a triacylglyceride and a lower alcohol as the methanol in the presence of a catalyst (JIANBING et al., 2006; PAIVA, 2010).

In the country, the most common biodiesel production route involves the homogeneous catalysis in a basic medium, using soybean oil and methanol as the raw material. However, the need for further steps for purification of the product in order to remove the remaining catalyst and salts present in the organic phase and non-reuse of the catalyst are some of the disadvantages of this route. As an alternative is mentioned the use of heterogeneous catalysts in the production of biodiesel (PRADANA et al., 2017). The performance of the catalysts is directly related to the nature of the acid or basic active sites.

The reaction may be carried out either in acid medium or in basic medium or using enzymes, homogeneously or heterogeneously. In acid catalysis are used, for example, sulfonic acid, sulfuric acid and hydrochloric acid. For the basic catalysis, alkali metal hydroxides, carbonates and alkali metal alkoxides are used, with emphasis on $\mathrm{NaOH}$ and $\mathrm{KOH}$, since a higher yield and selectivity were observed (KNOTHE, 2010) (FREEDMAN; BUTTERFIELD; PRYDE, 1986).

The most commonly used commercial technologies for biodiesel production employ bases such as $\mathrm{NaOH}$, or $\mathrm{KOH}$ as a catalyst, in methanol or ethanol solution. Such processes require a washing of the product with water in order to remove the dissolved catalyst and glycerol from the biodiesel, and may suffer from separation problems due to emulsion formation (MACALA et al., 2008).

In heterogeneous catalysis, the transesterification reaction can be catalyzed by a catalyst that is at different stages of the reactants. Several substances can be used as catalysts, for example: niobium oxide, iron oxide (magnetite and maguemite, used in this work), gold and silver, for example, and some of these substances can be applied to the surface of nanoparticles to the great advantage the increase of the surface area, better contact with the reactants and reuse of the catalyst. This process can be carried out in a fixed-bed reactor with advantages such as the mechanical stability of its particles (catalyst) and the greater ease of separation of reaction products (BORGES; DIAZ, 2012).

Nanostructured materials present great promise and opportunities for different applications, including catalysis, for a new generation of materials with controlled and optimized properties. The nanocatalysts have complex structures, different from the most known materials, with a high surface area in relation to the volume, which gives them unique properties, especially reactivity (FERREIRA; RANGEL, 2009)

In recent years, catalysts are prepared in nano-forms to improve catalytic activity, so nano-forms have a high specific surface area that increases the reaction rate. Calcium oxide by itself is cheap, highly reactive and easily available, and one of the most widely used solid catalysts for the transesterification reaction of different oils and fats to Biodiesel. One way to improve catalytic activity is to increase its specific surface by the preparation in its nanoform. The application of nano catalysts based on calcium oxide $(\mathrm{CaO})$ reaches degrees of conversion greater than $90 \%$ and are produced by several techniques (IVANA et al, 2017). The nanoparticles can be synthesized according to the top-down technique, and are generally prepared in the laboratory for batch production of biodiesel by the ball milling process. The raw material in powder form are precisely weighed and then placed separately in the ball mill and subjected to high collision energy coming from the balls. This process requires speed and time to obtain the required size catalyst. The nanoparticles are characterized by X-ray diffraction to determine the size and shape of the crystallite from the characteristic peaks of diffraction. (HASHMI et al., 2016).

Another example of nanocatalysts is the $\mathrm{TiO}_{2}-\mathrm{ZnO}$ mixed oxides, used in the production of biodiesel catalyzing the process of transesterification of palm oil, exhibiting good catalytic activity, with conversion of $92.2 \%$ to fatty acid methyl esters (FAME) achieved at $5 \mathrm{~h}$ at $60^{\circ} \mathrm{C}$ with a methanol / oil 
molar ratio of 6: 1 being observed in a loading of $200 \mathrm{mg}$ of catalyst. This type of mixture of oxides showed a good catalytic performance in relation to the $\mathrm{ZnO}$ catalyst, and could be a potential candidate for large scale biodiesel production (MADHUVILAKKU, R. and PIRAMAN, S., 2013).

The problem of using basic catalysts is due to the disadvantages already mentioned and adding the probability of the occurrence of saponification, the sensitivity to the presence of free fatty acids (FFA), contamination of the biodiesel with the catalyst, which restricts the use of raw material, with a low degree of purity, which makes the process more expensive. The use of a solid (heterogeneous) and nano-form catalyst would make the process feasible with materials of low purity, reducing part of the cost of the process, and therefore biodiesel, acting on the esterification and transesterification of these materials, such as frying oil , distilled from palm fat and animal fat, which contains high amounts of free fatty acids (MANSIR, N., et al, 2017).

In this context, it was proposed to study the transesterification of soybean oil with methanol in the presence of a cosolvent using as heterogeneous catalyst magnetic nanoparticles supported on silica in a fixed bed reactor. The cosolvents are used to overcome the solubility limitation between the reactants in the initial stages of the reaction, thus creating a single phase (KNOTHE, 2010). The reactions were conducted in a fixed bed reactor and also in erlenmeyers incubated at Shaker. A model to describe and simulate the process was proposed using the software Aspen Plus®.

\section{METHODS}

\subsection{Biodiesel Production Process Essays}

The biodiesel production process was carried out in batch, in two different ways, called kinetic tests and reactor tests. The kinetic assays were performed in Erlenmeyer incubators in Shaker, New Brunswick Scientific model Innova 43. The reagents were fed in the 1:6:5 molar ratio (soybean oil: methanol: tert-butanol), $3 \%$ silica supported nanocatalyst the amount of oil kept at $60{ }^{\circ} \mathrm{C}, 300 \mathrm{rpm}$ of stirring. Samples were collected at times ranging from 0.25 to 8 hours, centrifuged and the upper phase was taken for the chromatographic analysis which identified the formed methyl esters.

The reactor tests were carried out in a fixed bed, consisting of the glass wool compacted nanocatalyst, using proportions among reagents similar to those of the kinetic tests, working with recirculation of the reactants (emulsion initially containing soybean oil, methanol and tert-butanol), according to the scheme shown in figure 1 . The whole system was kept in thermostated bath at a temperature of $60^{\circ} \mathrm{C}$, keeping the fluid heated uniformly. A peristaltic pump Watson Marlon ${ }^{\circledR} 120 \mathrm{~S}$ was used to generate a flow from the lung vial (Emulsion) to the reactor. This flow was fed into the fixed bed reactor containing the silica supported nanocatalyst and the effluent from it returned to the lung vial.

The process was carried out in batch times of 6,8 and 10 h. Each sample was placed in a separating funnel so that the heavy (Alcohol) phases, composed of glycerol and methanol, and the light phase (Oil), consisting of the methyl esters, were partitioned. The separated phases were sent for analysis by gas chromatography.

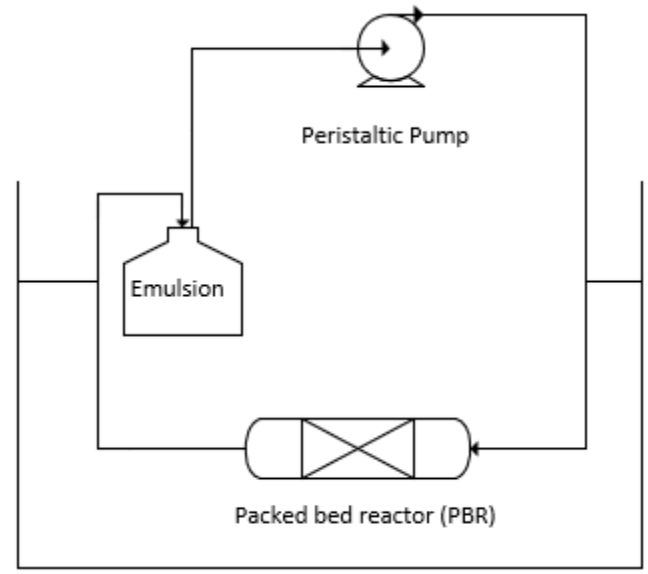

Figure 1 - Process flowsheet.

\subsection{Analysis of Biodiesel Conversion by Gas Chromatography}

The analysis of the biodiesel conversion of the methyl esters samples was performed by means of gas chromatography using Shimadzu Chromatograph (MDGC model MDGC/GCMS2010 with FID detector and a HT-5 column of $0.32 \mathrm{~mm} \times 25$ $\mathrm{m}$ and $0.1 \mu \mathrm{m}$ film thickness. Table 1 shows the operating conditions of the chromatograph. A split of 10 was used for the injections.

\begin{tabular}{ccc} 
Table 1 - CG-FID column temperature program \\
\hline Progress & Temperature $\left({ }^{\circ} \mathbf{C}\right)$ & Hold \\
\hline Start & 60 & 1 minute \\
Rate1 & 25 per mintute until 180 & 1 minute \\
Rate 2 & 5 per minute until 250 & 2 minutes \\
Rate 3 & 20 per minute until 300 & 2 minutes \\
Rate 4 & 30 per minute until 360 & 7 minutes \\
\hline
\end{tabular}

The concentration $C_{A, i}$ of each ester $i$ present in the aliquot (maliq) was calculated by equation 1 , in $\mathrm{mg} / \mathrm{mL}$. Since $A_{\text {peak,i }}$ is the area of the peak read on the chromatograph and $a_{i}$ the coefficient of the calibration curve.

$$
C_{A, i}=a_{i} A_{\text {peak }, i}
$$

From equation 1 and the hexane volumes $V_{d}$ used in the dilution, the mass $m_{A, i}$ of each ester in the aliquot was calculated by equation 2 , in $\mathrm{mg}$.

$$
m_{A, i}=C_{A, i} V_{\mathrm{d}}
$$

The ester mass fraction present in the aliquot $f_{A, i}$ was calculated by the ratio of the mass of each ester present in the aliquot $m_{A, i}$ by the mass of the maliq aliquot used for dilution. The calculation is represented in equation 3 .

$$
f_{A, i}=\frac{m_{A, i}}{\text { maliq }}
$$

Through equation 3 and the total mass of the phase containing the $m_{\text {exp }}$ methyl ester present in the separation funnel, the total mass of each ester $m_{i, t}$ in $\mathrm{g}$, was calculated by equation 4.

$$
m_{i, t}=f_{A, i} m_{\exp }
$$

The number of moles of each methyl ester $n_{i, t}$ was calculated by equation 4 and the molar mass of each ester $M i$. 


$$
n_{i, t}=\frac{m_{i, t}}{M_{i}}
$$

From equation 5 , the number of mols of biodiesel formed $\mathrm{n}_{\text {bprod }}$ by equation 6 was calculated.

$$
n_{\text {bprod }}=\sum n_{i, t}
$$

Taking into account that the stoichiometric ratio between soybean oil and methanol is 1 to 3 and the oil is the limiting reactant, the degree of conversion $X$ of biodiesel is determined by equation 7 , in which the $m_{\text {oil }}$ symbolizes the mass of soybean oil fed in $\mathrm{g}$ and $M_{\text {oil }}$ is the molar mass of soybean oil in $\mathrm{g} / \mathrm{mol}$.

$$
X=\frac{n_{\text {bprod }}}{3 \frac{m_{\text {oil }}}{M_{\text {oil }}}}
$$

\subsection{Computer Simulation Parameters}

The data obtained in the kinetic tests were used to determine the kinetic constant of the transesterification process using the tool Data Fit do software Aspen Plus V10 ${ }^{\circledR}$ which was also used to develop a model that represents the biodiesel production process. For the simulation of the process, the thermodynamic model UNIFAC was used and the database was the APV100biodiesel, which contemplates the majority of the components present in the reaction medium. Two types of reactors were studied for the transesterification, one to represent the fixed bed reactor (RPlug) and another reactor to represent the reactions in Erlenmeyer (Batch).

\section{RESULTS AND DISCUSSION}

\subsection{Batch Kinetic Essays Using Soybean oil, Methanol and tert-Butanol}

In order to determine the reaction kinetic constant using the software Aspen Plus V10 ${ }^{\circledR}$, Experimental Shaker tests were performed under the conditions presented in item 2.1. The erlemeyer assay, because it provides greater contact of the nanoparticulate catalyst with the reagents, is a better alternative for the acquisition of kinetic data than the proposed reactor. Using a refined soybean oil emulsion, methanol and tert-butanol (the cosolvent) in a ratio of 1: 6: 5, with a rotation of $300 \mathrm{rpm}$ and a constant temperature of $60^{\circ} \mathrm{C}$, in batch times ranging from 0.25 to 8 hour. The assays were performed and analyzed in duplicate by gas chromatography, and for each sample the average concentrations of methyl esters were obtained, as well as the average yield in biodiesel production, as a function of time, these data are found in Table 2. The degree of $X$ conversion of the oil phase present in each sample was calculated by equation 7 , with $X_{\text {average }}$ being the average degree of conversion of the samples. The conversion degrees of the

\begin{tabular}{|c|c|c|c|c|}
\hline Sample & $\begin{array}{c}\text { Reaction Time } \\
\text { (hours) }\end{array}$ & Phase & $X$ & $X_{\text {average }}$ \\
\hline 1 & 0,25 & Oil & $6,41 \%$ & \multirow{2}{*}{$6,96 \% \pm 0,0077$} \\
\hline 2 & 0,25 & Oil & $7,50 \%$ & \\
\hline 3 & 0,5 & Oil & $7,88 \%$ & \multirow{2}{*}{$7,74 \% \pm 0,0020$} \\
\hline 4 & 0,5 & Oil & $7,59 \%$ & \\
\hline 5 & 0,75 & Oil & $7,43 \%$ & \multirow{2}{*}{$7,81 \% \pm 0,0053$} \\
\hline 6 & 0,75 & Oil & $8,19 \%$ & \\
\hline 7 & 1 & Oil & $9,93 \%$ & \multirow{2}{*}{$10,07 \% \pm 0,0020$} \\
\hline 8 & 1 & Oil & $10,21 \%$ & \\
\hline 9 & 2 & Oil & $9,99 \%$ & \multirow{2}{*}{$10,09 \% \pm 0,0013$} \\
\hline 10 & 2 & Oil & $10,18 \%$ & \\
\hline 11 & 3 & Oil & $11,77 \%$ & \multirow{2}{*}{$15,14 \% \pm 0,048$} \\
\hline 12 & 3 & Oil & $18,50 \%$ & \\
\hline 13 & 4 & Oil & $21,80 \%$ & \multirow{2}{*}{$21,91 \% \pm 0,0015$} \\
\hline 14 & 4 & Oil & $22,02 \%$ & \\
\hline 15 & 5 & Oil & $22,35 \%$ & \multirow{2}{*}{$22,98 \% \pm 0,0089$} \\
\hline 16 & 5 & Oil & $23,62 \%$ & \\
\hline 17 & 6 & Oil & $26,02 \%$ & \multirow{2}{*}{$25,46 \% \pm 0,0079$} \\
\hline 18 & 6 & Oil & $24,90 \%$ & \\
\hline 19 & 7 & Oil & $25,36 \%$ & \multirow{2}{*}{$27,13 \% \pm 0,0251$} \\
\hline 20 & 7 & Oil & $28,91 \%$ & \\
\hline 21 & 8 & Oil & $32,34 \%$ & \multirow{2}{*}{$36,04 \% \pm 0,0522$} \\
\hline 22 & 8 & Oil & $39,73 \%$ & \\
\hline
\end{tabular}
samples are shown in Table 2.

Table 2 - Biodiesel converction and average converction over the time.

These results were later used as input data to obtain the kinetic constant and the process simulation in the software Aspen Plus V10 ${ }^{\circledR}$.

\subsection{Packed Bed Reactor Essays Using Soybean oil, Methanol and tert-Butanol}

Tests were performed using the fixed bed reactor system as shown in item 2.1, in order to compare the results obtained with the Shaker tests. Three batches were performed using the
1:6:5 molar ratio soybean oil/methanol/tert-butanol (cosolvent) at the respective 6,8 and 10 hour batch times. The degree of conversion of the samples was calculated as described in item 2.2. Using equations 5 and 7 , it was possible to calculate the number of mols of methyl esters $\left(n_{i, t}\right)$, the degree of conversion $(X)$ of each test in the light and heavy phases (Oil and Alcohol) as well as the total conversion $\left(X_{t o t}\right)$ calculated by summing the degree of conversion of the two phases of each sample. The conversion rates for each phase (Oil and Alcohol) for reaction 
times of 6,8 and 10 hours are shown in Table 3 .

Table 3 - Biodiesel converction in each fase and total, preliminary essays.

\begin{tabular}{ccccc}
$\begin{array}{c}\text { Reaction Time } \\
\text { (h) }\end{array}$ & Phase & $\sum n_{i, t}$ & $\boldsymbol{X}$ & $\boldsymbol{X}_{\text {tot }}$ \\
\multirow{2}{*}{6} & Oil & 0,000236 & $0,48 \%$ & \multirow{2}{*}{$0,66 \%$} \\
& Alcohol & 0,000085 & $0,18 \%$ & \\
\hline \multirow{2}{*}{8} & Oil & 0,000510 & $1,05 \%$ & \multirow{2}{*}{$1,50 \%$} \\
& Alcohol & 0,000223 & $0,46 \%$ & \\
\hline \multirow{2}{*}{10} & Oil & 0,001305 & $2,68 \%$ & \multirow{2}{*}{$3,18 \%$} \\
& Alcohol & 0,000245 & $0,50 \%$ & \\
\hline
\end{tabular}

The results obtained from the tests performed in the fixed bed reactor were well below those achieved in the Shaker tests, which can be observed by comparing the data presented in table 2 and 3.

Comparing the tests conducted in the reactor with 6 and 8 hour times with the conversion values obtained in the Shaker tests, the tests performed in the reactor reached values $97.4 \%$ and $95.8 \%$ lower than those performed in Shacker. Even the longest test with 10 hour duration, best result in the reactor, the conversion degree was $91.2 \%$ lower than the 8 hour time assay performed on Shaker. This fact can be justified by some observed factors, and described as discussed below. The high pressure loss of the compacted system, as well as the formation of preferential paths, certainly limited the contact time of the reactants with the nanocatalyst, thus reducing the catalysis of the reaction. Another possibility raised was the lack of spontaneous separation between the phases caused by the presence of a cosolvent, which does not contribute to the displacement of the chemical equilibrium formed reducing the degree of conversion obtained. Another hypothesis raised was the possible dilution of the system due to the use of cosolvent, the ratio of methanol: tert-butanol used was 6: 5 molar, which represents a volume ratio of 1:2. Although not an extremely high proportion, there may have been a dilution of the system, making contact between the reagents and between them and the nanocatalyst more difficult. This phenomenon, associated to the others described, could have been responsible for results so inferior obtained in the reactor when compared to the values of reactional conversions of Shaker tests. These hypotheses are corroborated by the results obtained in Shaker under the same operating conditions, but in the absence of the co-solvent, obtaining a degree of conversion of $66.37 \%$, in a test of 6 hours. This result is higher when compared to Shaker tests with the use of cosolvents, see table 2 .

\subsection{Computer Simulation Results}

From the data obtained in the kinetic assay and using the Data Fit tool of Aspen Plus V10 ${ }^{\circledR}$ software, the kinetic parameters of the reaction of transesterification of soybean oil with methanol were calculated using a heterogeneous nanocatalyst. Following the steps described in section 2.3 , it was possible by regression to obtain the values of the kinetic constant $(\mathrm{k})$ for the direct reaction $\left(0.0698 \mathrm{~h}^{-1}\right)$ and for the inverse reaction of $\left(6.81 \times 10^{-8} \mathrm{~h}^{-1}\right) . \neg$ These values are justified due to the high reaction time. It was also possible to obtain the biodiesel concentration data formed over time simulating the process through the software Aspen Plus $\mathrm{V}^{\circledR} 0^{\circledR}$.

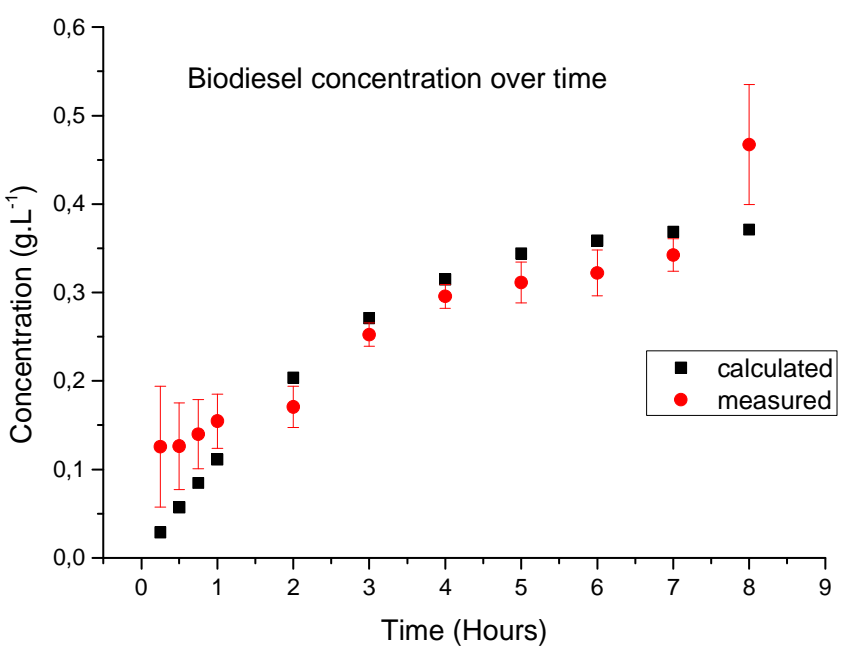

Figure 2 - Comparison of the curve of concentration of biodiesel over time for the values obtained experimentally and calculated by the model computacional.

In the graph, shown in Figure 2, it is possible to observe the concentration values of the methyl esters (biodiesel) as a function of time, obtained experimentally (measured) and predicted by the (calculated) model. When comparing the data obtained experimentally with the curve of the approximate function, obtained from the Data Fit tool, it can be seen that both have the same behavior, presenting only a small margin of error and can be justified by experimental errors during the reaction. With this, it can be said that the model describes the process well.

It is also possible to verify that in the considered time the system enters in balance approximately in the time of 7 hours. This effect can be explained by the presence of a cosolvent which at the beginning of the reaction is interesting due to its ability to miscible the initially immiscible oil and methanol. With the advancement of the reaction and consequent formation of the methyl esters and glycerol the reaction tends to equilibrium. It is plausible that the cosolvent provides the miscibility of the glycerol, disfavoring the piastes separation and thus not displacing the reaction towards the desired product. Consequently limiting the reaction in equilibrium. This fact is a possible justification for the low reactive yields achieved in the presence of cosolvents compared to the reactions conducted without the use of this type of substance.

\section{CONCLUSIONS}

The Shaker tests were performed under the following conditions: 1:6:5 oil/methanol/tert-butanol molar ratio, $60{ }^{\circ} \mathrm{C}$ temperature and $300 \mathrm{rpm}$ rotation in order to plot the biodiesel concentration ratio formed as a function of time. These results were used to calculate the kinetic reaction constant using the Aspen Plus V10® software. After obtaining the kinetic constant, it was used to simulate the continuous and batch process.

The best condition presented in the kinetic study was also tested in the fixed bed reactor, but the conversion degree values obtained were very low $(3.18 \%$ in $10 \mathrm{~h})$ when compared to the average value reached in shaker, in the time of 8 hours $(36.04 \%)$. The value obtained in Shaker is about 11 times greater when compared to the degree of conversion obtained in $10 \mathrm{~h}$ and 24 times when compared in the same time of $8 \mathrm{~h}$ 
$(1,50 \%)$. Due to the low values of the conversion degrees obtained in the tests conducted in the reactor, the studied times varied between 6,8 and 10 hours. Thus, in spite of low, a significant increase of biodiesel yield was detected for the transesterification reaction carried out in a fixed bed reactor using magnetic nanoparticles supported on silica under the following conditions: emulsion containing soybean oil, methanol and tert-butanol, with a 1:6:5 molar ratio at a constant temperature of $60{ }^{\circ} \mathrm{C}$. However, the degree of conversion achieved was still very low $(3.18 \%)$, due to the lack of agitation and the formation of preferential paths that decrease the contact between the nanoparticle (catalyst) and the emulsion. Another fact that may have been decisive is dilution caused by the cosolvent due to the proportion used approximately 2 times in volume in relation to the volume of methanol used in the reaction mixture. This is corroborated by the result obtained in shaker and without cosolvent, but under the same conditions, reaching a degree of conversion of $66.37 \%$.

During the simulation, it was possible to obtain the kinetic constants, so that the comparison of the obtained results of the biodiesel concentration through the simulation and obtained in the practice presented low standard deviations.

A C K N O W L E D G M EN T

To the FEI University Center and to the Laboratory of Supramolecular Chemistry and Nanotechnology of the Institute of Chemistry of the USP (LQSN) for the support for the development of the work.

\section{R E F E R E N C E S}

BORGES, M.B; DÍAZ, L. Catalytic Packed-Bed Reactor ConFiguration for BiodieselProduction Using Waste Oil as Feedstock. BioEnergy Research, v. 6, p. 222-228, 2012.

CARVALHO, J.F.D. Combustíveis fósseis e insustentabilidade. Ciência e cultura. v. 60 , n.3. São Paulo, 2008.

FERREIRA, H. S.; RANGEL, M., Nanotecnologia: aspectos gerais e potencial de aplicação em catálise. Quim. Nova, Vol. 32, No. 7, 1860-1870, 2009.

FREEDMAN, B.; BUTTERFIELD, R. O.; PRYDE, E. H. Transesterification kinetics of soybean oil. Journal of the American oil chemists' society, vol. 63, issue 10, p. 1375-1380, 1986.

HASHMI, S., GOHAR, S., MAHMOOD, T., NAWAZ, U., FAROOQI, H.; Biodiesel Production by using CaO$\mathrm{Al}_{2} \mathrm{O}_{3}$ nano catalyst, International Journal of Engineering Research \& Science, vol.2, issue 3, 43-49, 2016

IVANA B. BANKOVIC-ILIC, MARIJA R. MILADINOVIC, OLIVEIRA S. STAMENKOVIC, VLADA B. VELJKOVIC, Application of nano CaO-based catalysts in biodiesel synthesis, Renewable and Sustainable Energy Reviews, 72, 746-760, 2017.

JIANBING, JI et al. Preparation of biodiesel with the help of ultrasonic and hydrodynamic cavitation. Ultrasonics, $v$. 44, p. 411-414, 2006.

KNOTHE, G. The Biodiesel Handbook, Second Edition. Editora AOSC, Illinois, EUA, 2010.

MACALA, S.; ROBERTSON, W.; JOHNSON, C. L.; DAY, Z. B.; LEWIS, R. S.; WHITE, M. G.; IRETSKII, A. V.,
FORD, P. C. Transesterification Catalysts from Iron Doped Hydrotalcite-like Precursors: Solid Bases for Biodiesel Produtction. Catal Letters, 122, p.205-209, 2008.

MADHUVILAKKU, R; PIRAMAN, S.; Biodiesel synthesis by $\mathrm{TiO}_{2}-\mathrm{ZnO}$ mixed oxide nanocatalyst catalyzed palm oil transesterification process, Bioresource Technology, 150, 55-59, 2013.

MANSIR, N.; YUN HIN TAUFIQ-YAP; RASHID, U.; LOKMAN, I. M.; Investigation of heterogeneous solid acid catalyst performance on low grade feedstock for biodiesel production: A review; Energy Conversion and Management, 141, 171-182, 2017.

MUSA, I. A., The effects of alcohol to oil molar ratios and type of alcohol on Biodiesel production using transesterification process, Egyptian Journal of Petroleum, v.25, issue 1, p. 21-31, 2016.

OLIVEIRA, F. C. C.; SUAREZ, P. A. Z.; SANTOS, W. P.D; Biodiesel: Possibilidades e Desafios. Química e Sociedade, v. 28, maio, São Paulo, 2008.

PAIVA, E.J.M. Estudo da produção de Biodiesel a partir de Óleo de Babaçu e Etanol utilizando a Transesterificação Alcalina Tradicional com Agitação Mecânica e Assistida por Ultrassons. 2010. 173 f. Dissertação (Mestre em Ciências) - Universidade de São Paulo, Lorena, 2010.

PRADANA, Y.S et al. Biodiesel production in a reactive distillation collumn catalyzes by heterogeneous potassion catalyst, Energy Procedia, v. 143, p.742-747, 2017.

RAMOS, L. P et al. Tecnologias de Produção de Biodiesel. Virtual Quim., v. 3, n. 5, p. 385-405, 2011.

ROTHENBERG, G. Catalysis, concepts and green applications. Índia: Wiley-Vch, 2008. p.12-17

SHI, WEI; ZHAO, JING; YUAN, XING; WANG, SHENGTIAN; WANG, XIAOHONG; HUO, MINGXIN; Effects of Bronsted and Lewis Acidities on Catalytic of Heteropolyacids in Transesterification and Esterification Reactions, Chem. Eng. Technol., 35, No. 2, 347-352, 2012.

SCHUCHARDT, U.; SERCHELI, R.; VARGAS, R. M. Transesterification of Vegetable Oils: A Review. Journal of the Brazilian Chemical Society, v. 9, n. 3, 1998.

SHARMA, R. K; YADAV, M; GAWANDE, M. B. Ferrites and Ferrates: Chemistry and Applications in Sustainable Energy and Environmental Remediation.Capítulo 1: Silica-Coated Magnetic Nano-Particles: Application in Catalysis 2018.

SUZUTA, T. et al. Iron Oxide Catalysts Supported on Porous Silica for the Production of Biodiesel from Crude Jatropha Oil. J Am Oil Chem Soc., v. 89, n. 11, p. 19811989, 2012.

VERMA, P; SHARMA, M.P., Review of process parameters for Biodiesel production from different feedstock, Renewable and Sustainable Energy Reviews, 62, 10631071, 2016. 